\title{
Modified pid control design for roll fin actuator of nonlinear modelling of the fishing boat
}

\author{
Fuat Alarçin, Assoc. Prof., \\ Hakan Demirel, Assistant, \\ M. Ertugrul Su, Assistant, \\ Ahmet Yurtseven, Assistant, \\ Yildiz Technical University, Turkey
}

\begin{abstract}
This study aims to reduce roll motion of a fishing boat which arises from disturbing hydrodynamic effects by means of fin roll stabilizer. It is assured that roll motion with nonlinear damping and restoring moment coefficients are down to the desired level through classical PID and modified PID algorithms. At the time of sailing, stability, a very important concept, was examined using Lyapunov direct method taking initial conditions into consideration, and it was noted that the system was generally stable. In addition, NACA 0015 model was used for the fin roll stabilizer, and flow analysis was carried out with Computational Fluid Dynamics (CFD) method. In the simulation results, when the same gains were used, modified PID controller algorithms were relatively more effective compared to PID in the fin roll stabilizer system.
\end{abstract}

Keywords: stability analyses; nonlinear roll motion; modified PID; CFD

\section{INTRODUCTION}

Ships remain a research subject for researchers as they lack fundamentals about stability despite meeting the requirements of current laws. Roll motion is one of the most significant ship motions due to stability. Many publications concerning the ship roll motion were presented in literature $[2,5]$.

Solimon and Thompson [17] used Runga-Kutta method for analyze the nonlinear differential equation of roll motion. Haddara and Wang [7] examined the controllability and maneuvering performance of conventional surface ships using neural networks technique to predict the hydrodynamic parameters of the ship. Taylan [21] studied impact of nonlinear terms in ship rolling motion. Surendran and Reddy [18] revealed solution of differential equation of roll motion considering the nonlinearities in both the restoring moment and the damping moment using Matlab for a Ro-Ro ship. Karakaş et al. [12] analyzed nonlinear roll motion via a controller based on Lyapunov Direct Method in beam seas.

Safety of voyage has to be assured against the disrupting hydrodynamic effects of passengers as well as cargos, and amplitude has to be at an acceptable level. Therefore, a number of applications such as fin roll stabilizers and U-tube have been used in literature $[3,16,9]$.

There are many control methods which could be used to reduce roll motion. Surendran et al. [19] used active fins to minimize roll motion of a ship by means of the PID controller. Guan and Zhang [6] offered nonlinear fin roll control originated from integrator backstepping associated with nonlinear damping term. They simplified the standard nonlinear backstepping algorithm in use of the Close-loop Gain Shaping Algorithm (CGSA). It was expressed that roll amplitude was reduced of around $90 \%$ comparing with uncontrolled result in the same simulation conditions. Ghassemi et al. [4] referred to neural network-PID controller for roll fin stabilizer.

In this study, roll amplitude of a ship under the wave effect has been ensured to be at stable zone using the hydraulic fin roll stabilizer system based on the 3 rd level nonlinear damping effect and modeling 5 th level restoring moment coefficient. These coefficients of the rolling motion equation of the fishing vessel in waves were obtained using theoretical methods. Stability analysis was conducted using Lyapunov method. It is provided with a Matlab code to solve a second order differential equation with constant coefficients using Matlab in-built solver ODE45. In addition, Classical PID and Modified PID controller results demonstrate the effectiveness of the Modified PID controller.

\section{SHIP ROLL MOTION MATHEMATICAL MODEL}

Because of different environmental conditions, ship motions have not the same amplitude and acceleration so reducing degrees of freedom makes it easy to find a solution. Components that make up the physical model and mathematical model of single degree of freedom ship roll motion are generated from 
Taylan's [20] and Surendran's [19] previous studies and they are expressed on the basis of the following assumptions:

- ship is symmetric in the direction of port side and starboard side,

- all the other degrees of freedom of ship have been neglected,

- ship has been regarded as rigid body.

Considering some simplifications, the following nonlinear expression for the roll equation is obtained:

$$
\begin{gathered}
(\mathrm{I}+\mathrm{J}) \ddot{\emptyset}+\mathrm{B}_{1} \dot{\emptyset}+\mathrm{B}_{2} \dot{\emptyset}|\dot{\emptyset}|+\mathrm{B}_{3} \dot{\emptyset}^{3}+ \\
+\Delta\left(\mathrm{c}_{1} \emptyset+\mathrm{c}_{3} \emptyset^{3}+\mathrm{c}_{5} \emptyset^{5}+\mathrm{c}_{7} \emptyset^{7}\right)= \\
=\omega_{\mathrm{e}}{ }^{2} \propto_{\mathrm{m}} \mathrm{I} \cos \left(\omega_{\mathrm{e}} \mathrm{t}\right)-\mathrm{M}_{\mathrm{f}}
\end{gathered}
$$

Where $\mathrm{I}$ is the mass moment of inertia for roll and $\mathrm{J}$ is added mass moment of inertia for roll. $\mathrm{B}_{1}, \mathrm{~B}_{2}, \mathrm{~B}_{3}$, symbolize roll damping coefficients, $\mathrm{c}_{1}, \mathrm{c}_{3}, \mathrm{c}_{5}$ and $\mathrm{c}_{7}$ are expressed as restoring force coefficients. $\varnothing, \dot{\varnothing}, \ddot{\varnothing}$ represent angle, angular velocity and angular acceleration of roll motion respectively. $\Delta$ means the weight displacement of the ship, $\omega_{\mathrm{e}}$ means wave encountering frequency, $\alpha_{\mathrm{m}}$ means the maximum wave slope, $\mathrm{M}_{\mathrm{f}}$ means the control moment of active fins.

Inertia value has an important effect with regards to nonlinear roll motion. This value has been expressed as below based on weight displacement of ship, breadth and the vertical distance of the center of gravity [19].

$$
(\mathrm{I}+\mathrm{J})=\frac{\Delta}{12 \mathrm{~g}}\left(\mathrm{~B}^{2}+4 \mathrm{KG}^{2}\right)
$$

The roll damping coefficients are considered as skin friction of the hull, eddy shedding from the hull, free surface waves, lift effect damping and bilge keel damping. Theoretical and semiempirical methods have been used to utilize the roll damping by Ikeda and Himeno [11], Ikeda [10]. A non-dimensional damping coefficient for different ship types is expressed as follows.

$$
\begin{gathered}
\mathrm{B}_{1}=\frac{2 \mathrm{a} \sqrt{(\mathrm{I}+\mathrm{J}) \Delta \mathrm{GM}}}{\pi} \\
\mathrm{B}_{2}=\frac{3}{4} \mathrm{~b}(\mathrm{I}+\mathrm{J}) \\
\mathrm{B}_{3}=0.7 \mathrm{~B}_{2}
\end{gathered}
$$

These coefficients, given a and b in Tab. 1 [6], are directly related to a linear damping coefficients $\mathrm{B}_{1}$ and a non-linear damping coefficient, $\mathrm{B}_{2}$ represents quadratic drag and $\mathrm{B}_{3}$ is cubic [2].
Tab. 1. The non-dimensional damping coefficients for three different types of the ship

\begin{tabular}{|c|c|c|}
\hline Types of the ship & a & b \\
\hline Passenger ship & 0.05 & 0.0125 \\
\hline Cargo ship & 0.03 & 0.0155 \\
\hline Fishing ship & 0.1 & 0.0140 \\
\hline
\end{tabular}

The curve for righting arm has been represented by the polynomial.

$$
\mathrm{M}(\emptyset)=\mathrm{c}_{1} \emptyset+\mathrm{c}_{3} \emptyset^{3}+\mathrm{c}_{5} \emptyset^{5}+\mathrm{c}_{7} \emptyset^{7}+\cdots
$$

where: $c_{1}>0, c_{3}<0, c_{5}>0$ and $c_{7}<0$ for a damaged vessel but $\mathrm{c}_{7}=0$ for an intact vessel. The roll restoring moment coefficients are defined by Taylan [21].

$$
\begin{gathered}
\mathrm{c}_{1}=\frac{\mathrm{d}(\mathrm{GZ})}{\mathrm{d} \emptyset}=\mathrm{GM} \\
\mathrm{c}_{3}=\frac{4}{\emptyset_{\mathrm{V}}^{4}}\left(3 \mathrm{~A}_{\emptyset_{\mathrm{V}}}-\mathrm{GM} \emptyset_{\mathrm{V}}^{2}\right) \\
\mathrm{c}_{5}=-\frac{3}{\emptyset_{\mathrm{V}}^{6}}\left(4 \mathrm{~A}_{\emptyset_{\mathrm{V}}}-\mathrm{GM} \emptyset_{\mathrm{v}}^{2}\right)
\end{gathered}
$$

$\varnothing_{\mathrm{v}}$ means vanishing angle of stability, $\mathrm{A}_{\varnothing_{\mathrm{v}}}$ means area under the GZ curve up to angle of vanishing stability, GM represents the distance between the position of metacenter and the vertical center of gravity of the vessel. Depending on the abovereferred coefficients, numerical calculations were performed for a fishing boat, whose body plan is given Fig. 1 .

The righting arm curve of fishing boat is represented as graphical on Fig. 2. From this figure, it can be seen that lift develops in an approximately linear manner with an increasing angle of attack. The area under the curve is an indication a safety voyage against capsizing moments.

Because of the effects of high wave frequency, ship sailing on the sea generates undesired roll motion. The wave moment $\left(\mathrm{M}_{\mathrm{w}}\right)$ and the encounter frequency of the wave $\left(\omega_{\mathrm{e}}\right)$ can be calculated as follow;

$$
\begin{gathered}
M_{\mathrm{w}}: \omega_{\mathrm{e}}^{2} \propto_{\mathrm{m}} \mathrm{I} \cos \left(\omega_{\mathrm{e}} \mathrm{t}\right) \\
\omega_{\mathrm{e}}=\omega_{\mathrm{w}}-\frac{\omega_{\mathrm{w}}^{2}}{\mathrm{~g}} \operatorname{Vcos}\left(\mu_{\mathrm{w}}\right)
\end{gathered}
$$

$\omega_{\mathrm{w}}$ represents the wave frequency, $\alpha_{\mathrm{m}}$ represents the maximum wave slope, $\mu_{\mathrm{w}}$ represents the wave encounter angle of the ship. It can be seen that wave excitation will depend many different factors.
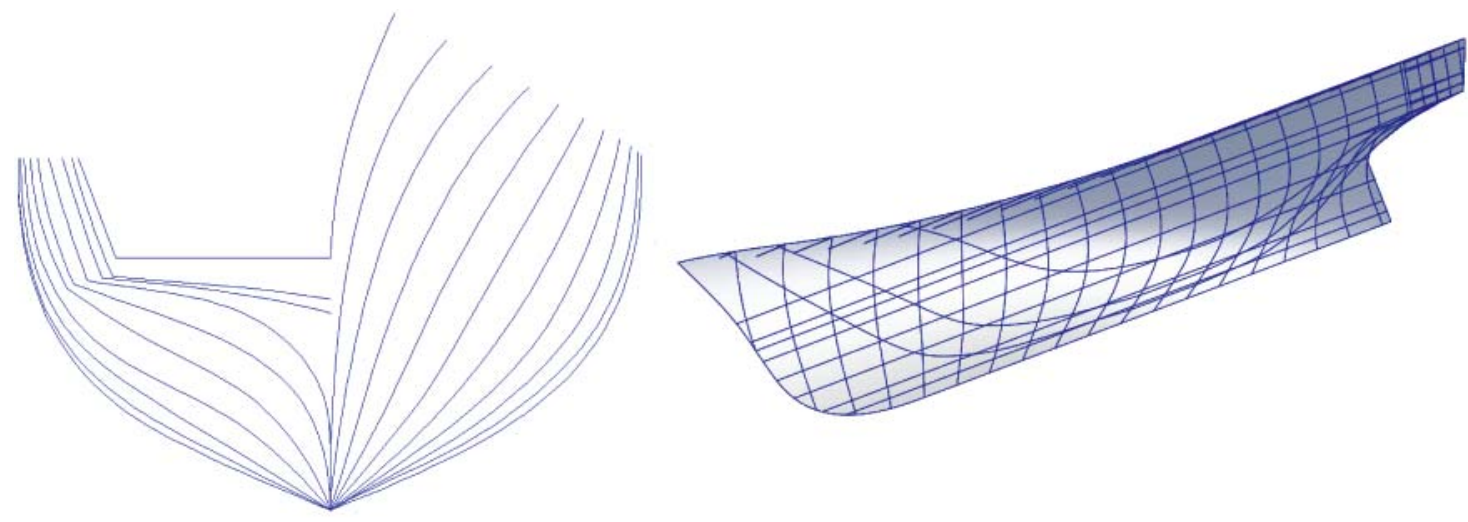

Fig. 1. Body plan of the fishing boat 


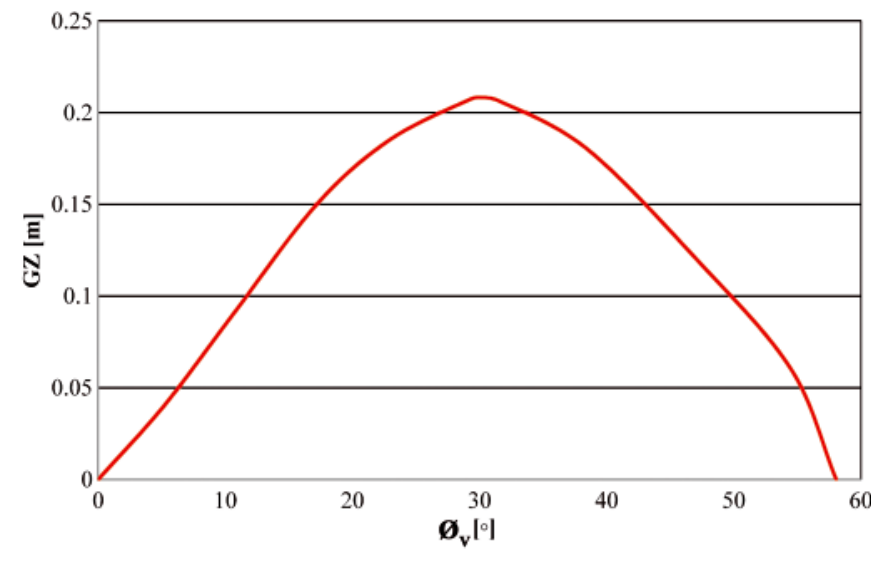

Fig. 2. Righting arm curve of fishing boat

\section{STABILITY ANALYSIS VIA LYAPUNOV'S DIRECT METHOD}

Stability analysis is a crucial subject for fishing boat. External forces like current weather and fishing conditions effect position of ship adversely. Fishing boat must have positive stability for safety voyage and fishing. Lyapunov's Direct Method was used for stability analyses by Ozkan [15]. This is a very robust and feasible method because it does not require any knowledge about the specific solutions of the equations. By using state variables of equation (1), the state space model of the ship can be written as:

$$
\begin{gathered}
\dot{\emptyset}=\dot{\emptyset}_{1}=\emptyset_{2} \\
\dot{\emptyset}_{2}=-\left(\omega_{0}^{2} \emptyset_{1}+\mathrm{m}_{3} \emptyset_{1}^{3}+\mathrm{m}_{5} \emptyset_{1}^{5}+\mathrm{m}_{7} \emptyset_{1}^{7}\right)+( \\
-\left(\mathrm{b}_{1} \emptyset_{2}-\mathrm{b}_{2} \emptyset_{2}\left|\emptyset_{2}\right|+\mathrm{b}_{3} \emptyset_{2}^{3}\right)
\end{gathered}
$$

Lyapunov function $\mathrm{V}(\mathrm{x})$ satisfying:

- $\mathrm{dV}(\overrightarrow{\mathrm{x}}) / \mathrm{dt} \leq 0$

- $\mathrm{V}(\mathrm{x}) \rightarrow \infty$ as $\|\mathrm{x}\| \rightarrow \infty$

Lyapunov second method will be used to test for the system stability.
- $\mathrm{V}(\mathrm{x})>0$ positive definite and $\mathrm{V}(0)=0$

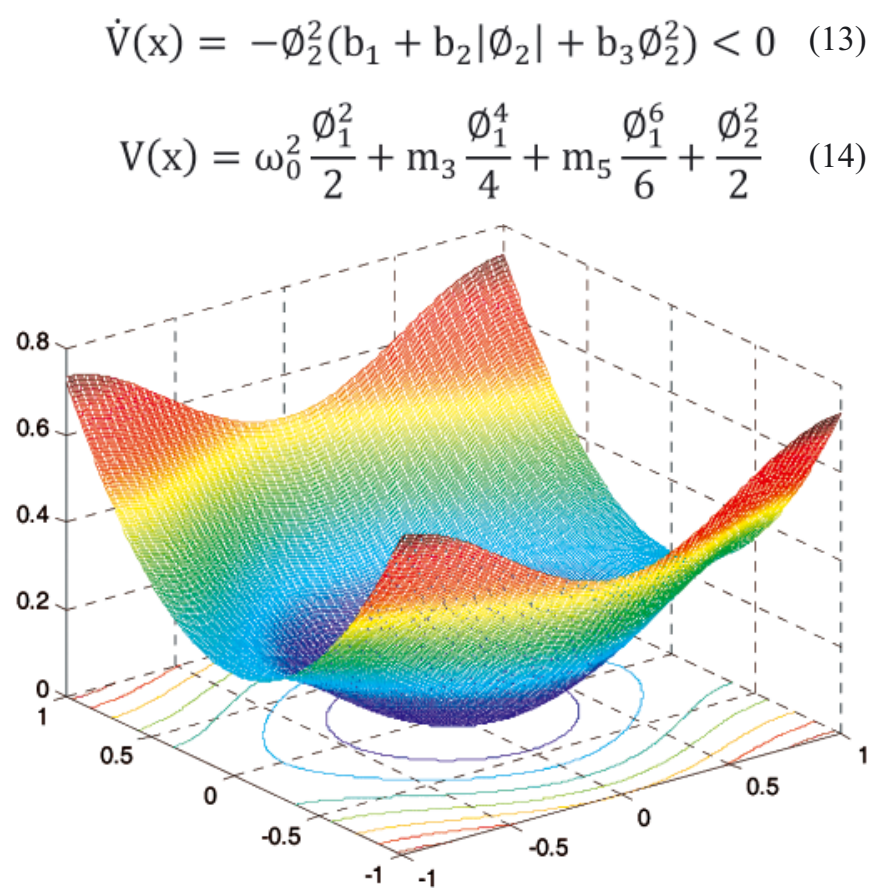

Fig. 3. Lyapunov function graphic

\section{FIN ROLL CONTROL DESIGN}

In this present work the fin-stabilizer consisted of two identical non-rectangular hydrofoils of a low aspect ratio, symmetrically placed on both sides of vessel. The motion of a ship can be affected by fins actuators that impart forces and moments. Actuators play a very important role within the control system structure. When the roll fin stabilizers attack to the fluid, it can be seen that the surface of fins lifting force caused by the rotation and angle of attack. The lift force and the lift in non-dimensional form is as in the following form [16]:

$$
\begin{aligned}
\mathrm{L} & =\frac{1}{2} \rho \mathrm{VA}_{\mathrm{F}} \mathrm{C}_{\mathrm{L}} \\
\mathrm{C}_{\mathrm{L}} & =\frac{\mathrm{L}}{0.5 \rho \mathrm{V}^{2} \mathrm{~A}_{\mathrm{F}}}
\end{aligned}
$$

$$
\dot{\mathrm{V}}(\mathrm{t})=\frac{\mathrm{dV}(\overrightarrow{\mathrm{x}})}{\mathrm{dt}}=\nabla \mathrm{V}^{\mathrm{T}} \overrightarrow{\dot{\mathrm{x}}}
$$

$$
\begin{gathered}
\frac{\mathrm{dV}}{\mathrm{dt}=\propto_{11} \emptyset_{1} \emptyset_{2}}+\propto_{12} \emptyset_{2}-\propto_{21} \omega_{0}^{2} \emptyset_{1}^{2}-\propto_{21} \mathrm{~m}_{3} \emptyset_{1}^{4}-\propto_{21} \mathrm{~m}_{5} \emptyset_{1}^{6}-\propto_{21} \mathrm{~m}_{7} \emptyset_{1}^{8}-\propto_{21} \mathrm{~b}_{1} \emptyset_{1} \emptyset_{2} \\
-\propto_{21} \mathrm{~b}_{2}\left|\emptyset_{2}\right| \emptyset_{1} \emptyset_{2}-\mathrm{b}_{3} \propto_{21} \emptyset_{1} \emptyset_{2}^{3}-\propto_{22} \omega_{0}^{2} \emptyset_{1} \emptyset_{2}-\propto_{22} \mathrm{~m}_{3} \emptyset_{1}^{3} \emptyset_{2} \\
-\propto_{22} \mathrm{~m}_{5} \emptyset_{1}^{5} \emptyset_{2}-\propto_{22} \mathrm{~b}_{1} \emptyset_{2}^{2}-\propto_{22} \mathrm{~b}_{2}\left|\emptyset_{2}\right| \emptyset_{2}^{2}-\propto_{22} \mathrm{~b}_{3} \emptyset_{2}^{4}
\end{gathered}
$$

If symmetric coefficients accept equal to zero, derivative of the Lyapunov function is negative; the conditions for asymptotic stability are found to be:

$$
\begin{gathered}
\frac{\mathrm{dV}}{\mathrm{dt}}=\emptyset_{1} \emptyset_{2}\left(\propto_{22} \omega_{0}^{2}+\mathrm{m}_{3} \propto_{22} \emptyset_{1}^{2}+\mathrm{m}_{5} \propto_{22} \emptyset_{1}^{4}-\propto_{22} \omega_{0}^{2}\right)-\propto_{22} \mathrm{~b}_{1} \emptyset_{2}^{2}-\propto_{22} \mathrm{~m}_{3} \emptyset_{1}^{3} \emptyset_{2} \\
-\propto_{22} \mathrm{~m}_{5} \emptyset_{1}^{5} \emptyset_{2}-\propto_{22} \mathrm{~b}_{2}\left|\emptyset_{2}\right| \emptyset_{2}^{2}-\propto_{22} \mathrm{~b}_{3} \emptyset_{2}^{4} \\
\propto_{11}=\propto_{22} \omega_{0}^{2}+\mathrm{m}_{3} \propto_{22} \emptyset_{1}^{2}+\mathrm{m}_{5} \propto_{22} \emptyset_{1}^{4}
\end{gathered}
$$

Lyapunov function is obtained depending on the non-linear roll damping coefficient. If this value is smaller than zero, nonlinear roll motion can be said to be stable. Lyapunov function graphic for the system is given in the Fig. 3. 
Where L lifting force $(N) ; \rho$ density of fluid $\left(t / \mathrm{m}^{3}\right) ; A_{F}$ fins area $\left(\mathrm{m}^{2}\right) ; \mathrm{C}_{\mathrm{L}}$ fins lift coefficient (lift coefficient/rad); V the ship speed $(\mathrm{m} / \mathrm{s})$. General formulas of fin roll stabilizer are expressed as the following equations.

$$
\mathrm{M}_{\mathrm{F}} \rho \mathrm{V}^{2} \mathrm{~A}_{\mathrm{F}} \mathrm{C}_{\mathrm{L}} \mathrm{l}_{\mathrm{F}}\left(\propto_{\mathrm{f}}+\frac{\dot{\emptyset}}{\mathrm{V}} \mathrm{l}_{\mathrm{F}}\right)
$$

Where $\mathrm{M}_{\mathrm{F}}$, fin roll stabilizer moment; $1_{\mathrm{F}}$ the fins force arm; $\alpha$ angle attack. The result of hydrodynamic lift coefficient in function of attack angle of fin and roll angle of ship are presented in Fig. 4.

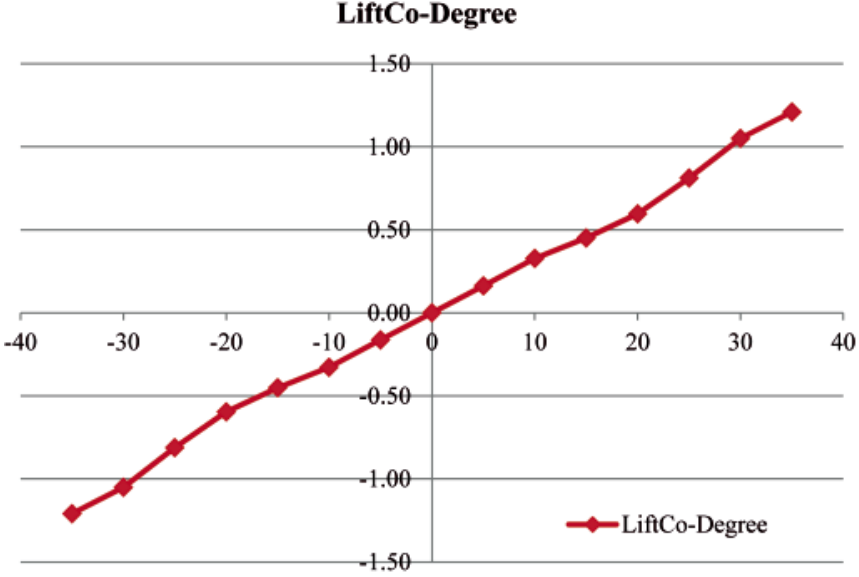

Fig. 4. Lift coefficient

Simulation was performed via 8 Parallel Processor and 24 GB of RAM hardware configuration. Fin was modeled in CFD package Star $\mathrm{CCM}+$. Preprocessing, running and finishing parts were integrated in the program. At the time of Preprocessing, Trimmer, Surface Remesher and Prism Layer Masher solution mesh properties were actualized concurrently. Mesh created consisted of 970000 cells and 2900000 faces. A sample case of free surface shape around fin is presented Fig. 5.

We conceived only a magnitude constraint for the mechanical angle of the fins of $20^{\circ}$. Segregated flow, reynolds averaged Navier Stokes and k- $\varepsilon$ turbulence model were used as solver to process of running. Convergence conditions are nearly $1 \mathrm{E}-5\left(10^{-5}\right)$. Running is performed in parallel with 8 cores. In conclusion, the velocity and pressure gradients are obtained; the lift force coefficient was expressed by means of the model.

\section{Modified pid controller}

The classiccal PID controllers are the simplest form of controllers, and have being widely used satisfactorily in the field of process control systems. As seen in Fig. 6, it has basic and comprehensible structure. The classiccal PID controller of a plant is shown in Fig. 6 [14].

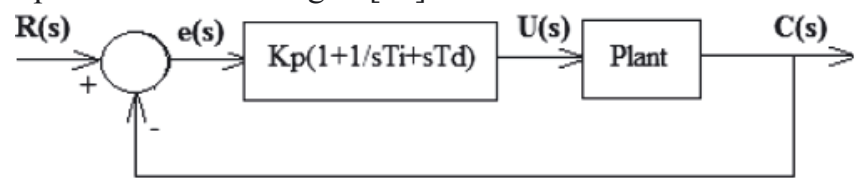

Fig. 6. Classiccal PID controller of a plant

$\mathrm{R}(\mathrm{s})$ and $\mathrm{C}(\mathrm{s})$ indicate input and output signal, respectively. $K_{p}$ is proportional gain. $T_{i}$ and $T_{d}$ are integral and derivative time constant, respectively. $\mathrm{U}(\mathrm{s})$ is the manipulated signal. $\mathrm{e}(\mathrm{s})$ is differential signal between input and output signal. In time domain transfer function of classiccal PID controller is given below:

$$
\mathrm{G}_{\text {pid }}(\mathrm{t})=\mathrm{K}_{\mathrm{p}}\left[\mathrm{e}(\mathrm{t})+\frac{1}{\mathrm{~T}_{\mathrm{i}}} \int \mathrm{e}(\mathrm{t}) \mathrm{dt}+\mathrm{T}_{\mathrm{d}} \frac{\mathrm{de}(\mathrm{t})}{\mathrm{dt}}\right]
$$

where: $\mathrm{K}_{\mathrm{p}}$ indicates proportional gain of controller. $\mathrm{T}_{\mathrm{i}}=\mathrm{K}_{\mathrm{p}} / \mathrm{K}_{\mathrm{i}}$, $\mathrm{T}_{\mathrm{d}}=\mathrm{K}_{\mathrm{d}} / \mathrm{K}_{\mathrm{p}}$ and $\mathrm{e}$ is the error between the reference and the output system, $\mathrm{T}_{\mathrm{i}}$ is the intregral time, $\mathrm{T}_{\mathrm{d}}$ is derivative time. The Laplace transform of the equation (18) is expressed in (19)

$$
\mathrm{G}_{\text {pid }}(\mathrm{s})=\left(\mathrm{K}_{\mathrm{p}}+\frac{\mathrm{K}_{\mathrm{i}}}{\mathrm{s}}+\mathrm{sK}_{\mathrm{d}}\right)
$$

$\mathrm{K}_{\mathrm{i}}$ and $\mathrm{K}_{\mathrm{d}}$ are integral and derivative gains, respectively. The easy implementation and clear control principle of this controller makes it popular in many applications $[22,23$, $24,8]$.

But they have some disadvantages that they may not provide optimum result, and can not keep desired result in some situations. So as to deal with this issue and have optimal control classiccal PID controller can be modified. While integral part stays remained, proportional and derivative action move to the feedback path so that any change of reference input signal may not being involved in the manipulated signal. The model of closed loop system with Modified PID is shown in Fig. 7.

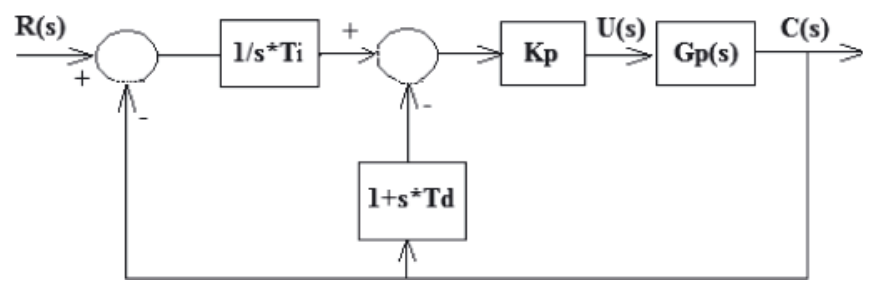

Fig. 7. The model of closed loop system with modified PID controller
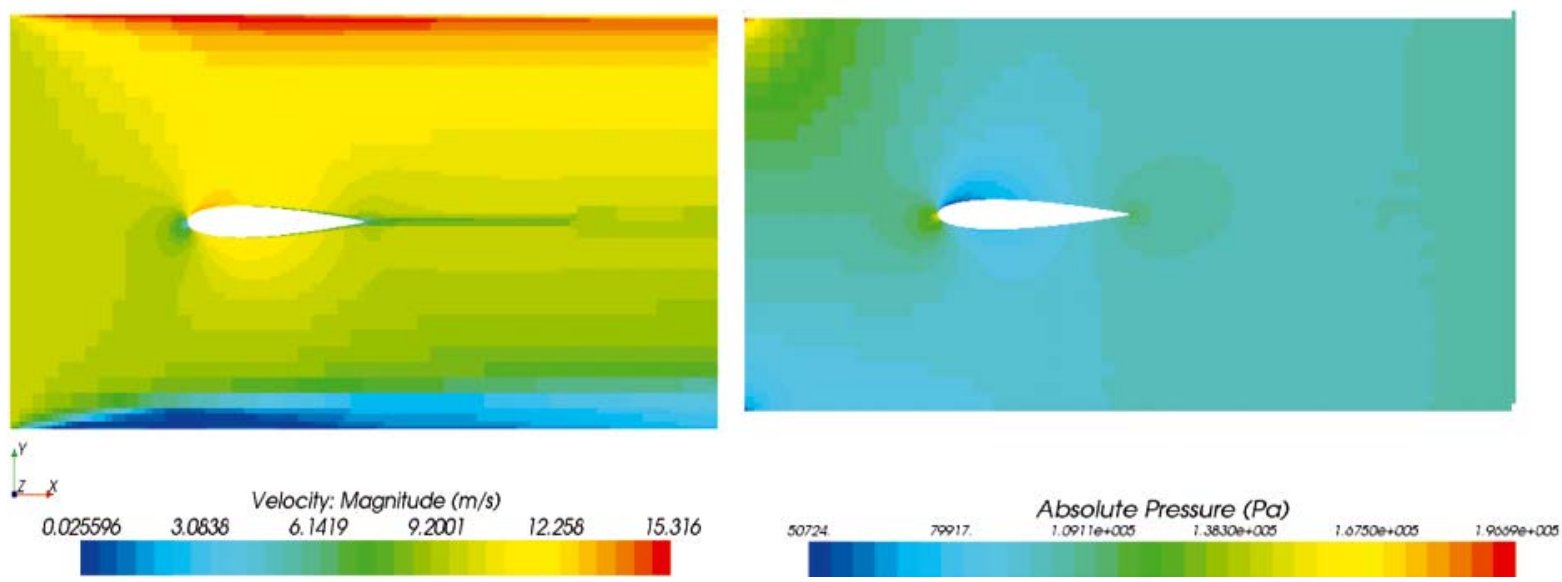

Fig. 5. Velocity and pressure gradient cross section (attack angle $+20^{\circ}$ ) 
The modified PID controller signal is demonstrated as follow:

$\mathrm{U}(\mathrm{s})=\mathrm{Kp} \frac{1}{\mathrm{sTi}} \mathrm{R}(\mathrm{s})-\mathrm{Kp}\left(1+\frac{1}{\mathrm{sTi}}+\mathrm{sTd}\right)$

Prettier form of controller can be given as follow:

$\mathrm{U}(\mathrm{s})=\frac{\mathrm{Kp} * \mathrm{R}(\mathrm{s})-\mathrm{sTi} * \mathrm{Kp}-\mathrm{Kp}-\mathrm{s}^{2} \mathrm{TiTd} * \mathrm{Kp}}{\mathrm{sTi}}$

Transfer function of closed loop system with modified PID controller is given below:

$\frac{\mathrm{C}(\mathrm{s})}{\mathrm{R}(\mathrm{s})}=\left(\frac{1}{\mathrm{sTi}}\right) \frac{\mathrm{KpGp}(\mathrm{s})}{1+\operatorname{KpGp}(\mathrm{s})\left(1+\frac{1}{\mathrm{sTi}}+\mathrm{sTd}\right)}$

After one more step transfer function can be obtained:

$\frac{\mathrm{C}(\mathrm{s})}{\mathrm{R}(\mathrm{s})}=\frac{\mathrm{KpGp}(\mathrm{s})}{\mathrm{s}^{2} \mathrm{KpGp}(\mathrm{s}) \mathrm{TdTi}+\mathrm{sKpGp}(\mathrm{s}) \mathrm{Ti}+2 \mathrm{KpGp}(\mathrm{s})}$

As seen in above equation the system with Modified PID controller has no zeros. Its advantages are to prevent earlier peak and higher overshoot. The proposed Modified PID controller can prevent this negative effect as well as can ameliorate system response in comparison with classiccal PID.

\section{SIMULATION}

Among 13 different fishing boats with different block coefficient examined in both loaded and unloaded conditions, the model in the table below was taken as a basic one [1]. These fishing boats have same length, breadth, depth and draught but cross-sectional forms are different. In this case, a stability characteristic varies with block coefficient from geometric characteristics. Our model and fishing boat and the fin (NACA 0015) particulars are showed in Tab. 2.

Tab. 2. The fishing boat and the fin (NACA 0015) particulars

\begin{tabular}{|c|c|}
\hline Principal Particulars & Parameter \\
\hline Length between perpendiculars $\left(\mathrm{L}_{\mathrm{BP}}\right)$ & $20 \mathrm{~m}$ \\
\hline Breadth $(\mathrm{B})$ & $5.714 \mathrm{~m}$ \\
\hline Depth $(\mathrm{D})$ & $3.2 \mathrm{~m}$ \\
\hline Draught $(\mathrm{T})$ & $2.285 \mathrm{~m}$ \\
\hline Displacement $(\nabla)$ & $119.34 \mathrm{~m}^{3}$ \\
\hline Transverse metacentric height $(\mathrm{GM})$ & $0.57 \mathrm{~m}$ \\
\hline Vertical center of gravity $(\mathrm{KG})$ & $2.4 \mathrm{~m}$ \\
\hline Block coefficient $\left(\mathrm{C}_{\mathrm{B}}\right)$ & 0.457 \\
\hline Service speed $(\mathrm{V})$ & $10 \mathrm{kn}$ \\
\hline Fins area $\left(\mathrm{A}_{\mathrm{F}}\right)$ & $2.5 \mathrm{~m}^{2}$ \\
\hline Fins lift coefficient $\left(\mathrm{C}_{\mathrm{L}}\right)$ & 0.59 \\
\hline Vanishing angle of stability $\left(\emptyset_{\mathrm{v}}\right)$ & $58^{\circ}$ \\
\hline
\end{tabular}

The simulation results for fin roll stabilizer system show roll angle and roll velocity in Fig. 8 and Fig. 9, respectively. Comparisons of the control performance are made between Classical PID and the MPID controllers.
The classical PID controller has given good result in considering of roll angle oscillation values. Nevertheless it still appears a steady error on time. On the other hand MPID halves the oscillation and error. Also in 10 seconds it prevents higher peak, which means avoid from higher roll angle.

The modified PID control response of the fin roll stabilizer is better than PID control as shown in Fig. 9. Although classical PID model has given almost same response such as the uncontrolled model, MPID model has ameliorated the fin roll velocity in range of -0.9 and 0.9 .

Non-dimensional damping coefficients $\left(b_{1}=0.069, b_{2}=0.01\right.$, $\left.\mathrm{b}_{3}=0.007\right)$ and restoring moment coefficients $\left(\mathrm{m}_{1}=1.204\right.$, $\mathrm{m}_{3}=-1.8, \mathrm{~m}_{5}=0.61, \mathrm{~m}_{7}=0$ ) for fishing boat were calculated by empirical formulas. $\mathrm{K}_{\mathrm{p}}, \mathrm{K}_{\mathrm{i}}$ and $\mathrm{K}_{\mathrm{d}}$ control values were obtained by trial method. The values of PID gains $\mathrm{K}_{\mathrm{p}}=0.2145, \mathrm{~K}_{\mathrm{d}}=$ $=1.2288, \mathrm{~K}_{\mathrm{i}}=2.89$ were ensured good roll reduction.

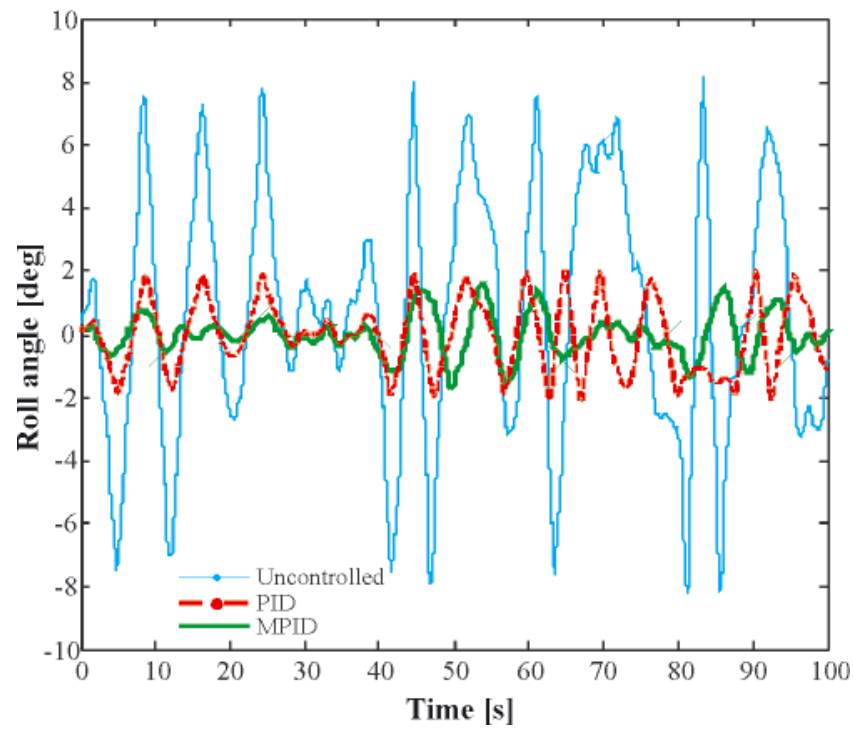

Fig. 8. Comparison of roll angle response

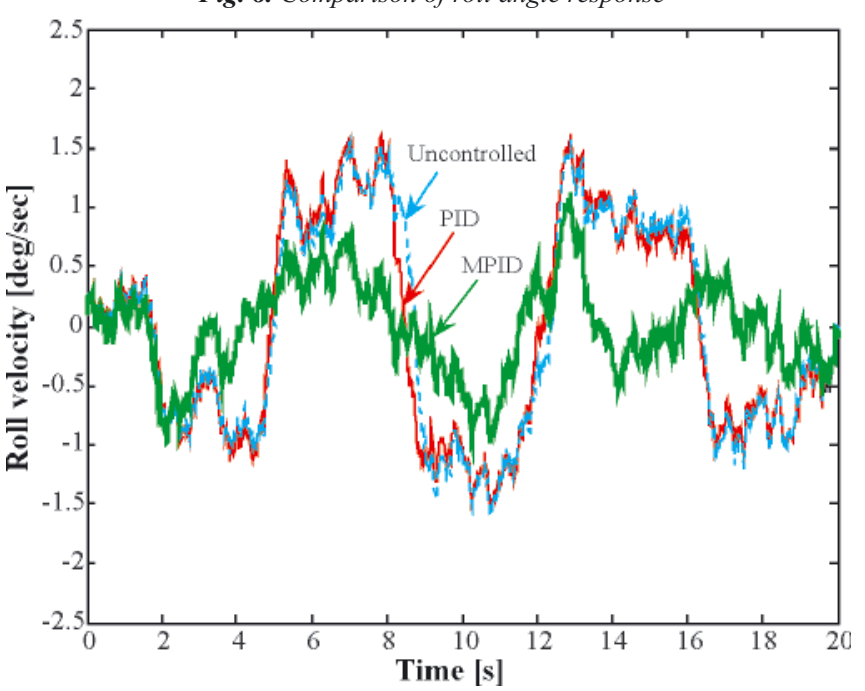

Fig. 9. Comparison of roll velocity response

In order to make fair comparison the step responses of two controllers with same gains are plotted in Fig. 10. Although PID has no early peak and nearly overshoots, MPID keeps stabilizing faster than Classical PID. Its early peak does not affect plant in a bad way. They give the almost same solution in settling time. Gains are calculated from the three terms of the process.

The comparison of the two controllers is presented in Tab. 3, which shows roll angle and roll velocity. The settling time for 


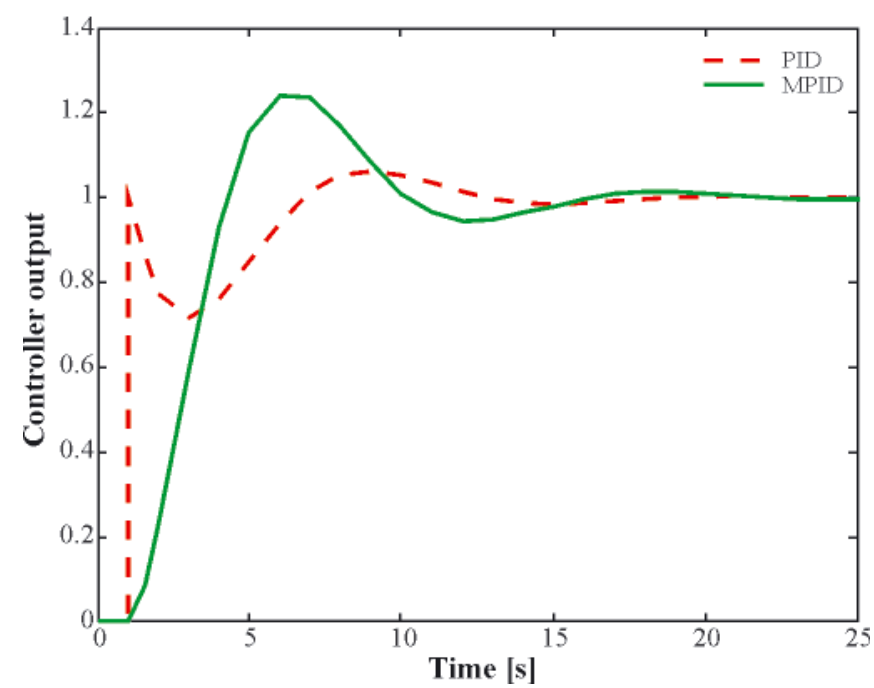

Fig. 10. Step responses of PID and MPID

uncontrolled is longer compared to the time for settlement of MPID.

Tab. 3. Performance Comparisons

\begin{tabular}{|c|c|c|}
\hline Controller & $\begin{array}{c}\text { Max. roll angle } \\
{[\mathbf{d e g}]}\end{array}$ & $\begin{array}{c}\text { Max. roll velocity } \\
{[\mathbf{d e g} / \mathbf{s}]}\end{array}$ \\
\hline Uncontrolled & $7.5^{\circ}$ & 1.5 \\
\hline PID & $2^{\circ}$ & 1.3 \\
\hline MPID & $1^{\circ}$ & 0.8 \\
\hline
\end{tabular}

Roll reduction ratio $\left(\mathrm{R}_{\mathrm{r}}\right)$ is used as the criteria for the roll reduction performance [13].

$$
\mathrm{R}_{\mathrm{r}}=\mathrm{M}_{\mathrm{fn}}-\mathrm{M}_{\mathrm{fs}}
$$

Where $R_{r}$ is rolling magnification, in case of actuation of the fins and rolling magnification $\mathrm{M}_{\mathrm{fn}}$ in case of non-actuation of the fins can be use.

\section{RESULTS}

This paper presents mathematical modeling and control of nonlinear roll motion with fin stabilizer system. The nonlinear terms which takes restoring and damping moment coefficients are calculated by empirical equations. The stability of nonlinear rolling motion of fishing boat is analyzed by Lyapunov direct method. During the simulation, it was assumed that the control gains are accepted same values for PID and MPID algorithms. From the simulation results, it can be observed that MPID controller shows significant improvement in roll magnitude around $86.6 \%$. MPID controller performance had $13.3 \%$ greater than PID as shown in Tab. 3.

\section{BIBLIOGRAPHY}

1. Aydın M. and Akyıldız H.: Assessment of the Intact Stability Characteristics of the Fishing Boats Suitable for Turkish Water. ITU publications Vol. 4, No.6, 2005.

2. Dalzell J.F.: A Note on the Form of Ship Roll Damping, Journal of Ship Research, Vol. 22, 1978.

3. Fossen T.I.: Guidance and Control of Ocean Vehicles, John Wiley\&Sons, 1994

4. Ghassemi H., Dadmarzi F.H., Ghadimi P., Ommani B.: Neural Network-PID Controller for Roll Fin Stabilizer. Polish Maritime Research 2(65) Vol. 17, 2010.

5. Grim O., Roll schwingungen, Stabilitat und Sicherheit in Seegang, Schiffstechnik, 1952.
6. Guan W., Zhang X. K.: Concise Robust Fin Roll Stabilizer Design Based on Integrator Backstepping and CGSA, IEEE, $1 / 10,2010$.

7. Haddara M. and Wang Y.: Parametric Identification of Maneuvering Models for Ships, Int. Shipbuild. Programs, 445 , pp. 5-27, 1999.

8. Hagiwara T., Yamada K., Ando Y., Murakamı I., Aoyama S., Matsuura S.: A Design Method For Modified PID Control Systems For Multiple-Input, multiple-Output Plants To Attenuate Unknown Disturbances, World Automation Congress. 2010.

9. Holden C. and Fossen T. I.: A Nonlinear 7-DOF Model for U-Tanks of Arbitrary Shape, Ocean Engineering 45, pp. 22-37, 2012.

10.Ikeda Y., Prediction Methods of Roll Damping of Ships and their Application to Determine Optimum Stabilization Devices, Proc, $6^{\text {th }}$ Int. Workshop on stability, 2002.

11.Ikeda Y., HimenoY., Tanaka N.: New York A Prediction Method for Ship Roll Damping, Report No. 00405 of the Department of Naval Architecture, University of Osaka Prefecture, 1978.

12.Karakas Ş.C., Uçer E., Pesman E.: Control Design of Fin Roll Stabilization in Beam Seas Based on Lyapunov's Direct Method, Polish Maritime Research 2 (73), Vol. 19, 2012.

13.Kawazoe T., Nishikido S., Wada Y.: Effect of Fin Area and Control Methods on Reduction of Roll Motion with Fin Stabilizer, Bulletin of the M.E.S.J, Vol.22.No.1, 1994.

14.Ogata K.: Modern Control Engineering, Prentice-Hall, 4th Edition, New Jersey, 1990.

15.Ozkan I.R.: Lyapunov's Direct Method for Stability Analysis of Ships' ITU, PhD dissertation, 1977.

16.Perez T., Goodwin G.C.: Constrained predictive Control of Ship Fin Stabilizers to Prevent Dynamic Stall, Control Engineering Practice 16, pp. 482-494, 2008.

17.Soliman M., and Thompson J.M.T.: Transient and Steady State Analysis of Capsize Phenomena, Applied Ocean Research, 13, pp. 82-92, 1991.

18.Surendran, S., Venkata Ramana Reddy, R., Roll dynamics of a Ro-Ro ship, International ship building progress, Vol. 49, No.4 pp. 301-320, 2002.

19.Surendran S., Lee S.K., Kim S.Y.: Studies on an Algorithm to Control the Roll Motion Using Active Fins, Ocean Engineering 34, pp. 542-551, 2007.

20.Taylan M.: Solution of the Nonlinear Roll Model by a Generalized Asymptotic Method, Ocean Engineering, Vol.26, pp. 1169-1181, 1999.

21.Taylan M.: The Effect of Nonlinear Damping and Restoring in Ship Rolling, Ocean Engineering, Vol.27, pp. 921-932, 2000.

22.Visioli A.: Modified anti-windup Scheme for PID Controllers. IEE Proc.-Cont. Theory App., 150, No 1. 2003.

23. Yamada K., Matsushima N. and Hagiwara T.: A Design Method for Modified PID Controllers for Stable Plants and Their Application. ECTI Transactions on Electrical Eng., Electronics and Communications Vol. 5, No. 1, 2007.

24.Concepción A. Monje, Blas M. Vinagre, Vicente Feliu, YangQuan Chen, Tuning and auto-tuning of fractional order controllers for industry applications, Control Engineering Practice, Volume 16, Issue 7, pp. 798-812, July 2008.

\section{CONTACT WITH THE AUTHORS}

Fuat Alarçin, Assoc. Prof., e-mail: alarcin@yildiz.edu.tr Hakan Demirel, Assistant, e-mail: demirelh@yildiz.edu.tr M. Ertugrul Su, Assistant, e-mail: mesu@yildiz.edu.tr Ahmet Yurtseven, Assistant, e-mail: ahmety@yildiz.edu.tr

Faculty of Naval Architecture and Maritime, Yıldız Technical University, Barbaros Bulvari Besiktas Istanbul TURKEY 34349 